\title{
“(...) O mundo como representação (...) é antes de tudo apenas um fenômeno fisiológico": Intuição intelectual e percepção empírica em Arthur Schopenhauer ${ }^{1}$
}

\author{
André Luis Muniz Garcia \\ Doutor em Filosofia pela UNICAMP \\ Professor do Departamento de Filosofia da Universidade de Brasilia \\ E-mail: andrelmg@unb.br
}

\begin{abstract}
RESUMO: O presente artigo tem por objetivo discutir alguns dos principais argumentos de Arthur Schopenhauer sobre as condições de possibilidade do conhecimento a priori da experiência. Para tanto, pretende-se aqui esclarecer o fundamental papel que a perspectiva científica - notadamente aquela da fisiologia - tem em sua doutrina da intuição intelectual tal como essa aparece em diferentes obras do filósofo alemão.
\end{abstract}

PALAVRAS-CHAVE: Schopenhauer, fisiologia, intuição intelectual.

ABSTRACT: The goal of the present article is to explain some of the most important arguments Arthur Schopenhauer's concerning to the conditions of possibilities of the a priori knowledge. For this, here I intend to elucidate the fundamental role that the scientific perspective - particulary that of physiology - plays in his theory of intellectual intution, such as it appears in differents works of the german philosopher.

KEY WORDS: Schopenhauer, physiology, intelectual intuition.

\section{Filosofar à maneira dos "ingleses": Schopenhauer e o pensar científico}

Quando pesquisadores do pensamento de F. Nietzsche se ocupam em mostrar sua história de recepção e de crítica da filosofia de Arthur Schopenhauer, quase que de modo unânime sobressaem temas referentes à metafísica da vontade, à compaixão, ao conceito de gênio, bem como - e isso devido à uma forte intensificação temática no assim chamado "último" Nietzsche - ao tema do pessimismo. Com rigor, tratou-se por muito tempo na pesquisa-Nietzsche da influência do grande "educador" sobre seu confesso discípulo, mas chega a ser curioso o fato de que que no âmbito da pesquisa (internacional) não haja hoje uma pregnante, cuidadosa e historicamente embasada obra-referência (como existe no caso de outros filósofos), a qual pudesse estabelecer, de modo a nortear os horizontes de toda

\footnotetext{
${ }^{1} \mathrm{O}$ presente artigo é parte modificada de um tópico do terceiro capítulo da dissertação de mestrado do autor, intitulada: Metáforas do corpo: reflexões sobre o estatuto da linguagem na filosofia do jovem Nietzsche, orientada pelo prof. Dr. Oswaldo Giacoia Jr, junto ao Departamento de Pós-Graduação em Filosofia da Universidade Estadual de Campinas, e que foi defendida em abril de 2008.
} 
pesquisa ulterior, uma reflexão crítica sobre a história de recepção e da assim chamada "ruptura" de Nietzsche com relação a Schopenhauer. Os motivos que impediram a produção de uma obra-referência que direcionasse a relação entre os dois filósofos está longe de ser objeto desse artigo; pelo contrário: talvez fosse nossa intenção aprofundar as dificuldades que perfazem tal tarefa, já que, à contramão da pesquisa desenvolvida sobre tal relação, não nos ocuparemos em apontar ou defender um dos dois, por assim dizer, "momentos" mais caros da pesquisa feita até o presente, quais sejam, aquela que traça, temporalmente, a influência da metafísica da vontade Schopenhauer, que caracteriza o assim chamado período de juventude de Nietzsche, e aquele que marca o "momento" de ruptura, quando da escrita, em 1878, do primeiro volume de Humano, Demasiado Humano. ${ }^{2}$ Queremos aqui, no entanto, pensar uma terceira margem, uma via que viabilize aprofundar o papel da influência de Schopenhauer no momento de ruptura (no assim chamado período intermediário), se é que podemos trabalhar com tais referências de modo tão livre.

Dizer, com precisão, o que é influência e o que é ruptura, em filosofia, e mais precisamente no caso de Nietzsche, é sempre problemático, devido à imprecisão da cisão cronológica de um pensamento - recorde-se que a divisão em três fases do pensamento nietzscheano foi esboçada, há muito, sem um aparato histórico-filosófico criterioso, por Lou Andreas-Salomé. Todavia, é justamente no famoso período de sua vigorosa invectiva contra a metafísica de Schopenhauer, no qual parecia improvável uma aproximação com seu antigo educador devido à sua forte crença na metodologia das ciências positivas, que Nietzsche enfatiza possíveis pontos positivos da contribuição filosófica de Schopenhauer, já que com Humano, Demasiado Humano I inaugura-se uma nova fase intelectual, na qual a metafísica, para dizer o mínimo, se tornou inócua ${ }^{3}$.

Na Gaia Ciência 99, portanto, nos últimos anos do assim chamado período intermediário, Nietzsche volta a tratar de uma temática a ele muito cara: a recepção da

\footnotetext{
${ }^{2}$ Em um material preparatório para o prefácio de Humano, Demasiado Humano, Nietzsche escreve retrospectivamente sobre seus escritos de juventude: "Aos leitores dos meus primeiros escritos gostaria de esclarecer que eu abandonei àquelas posições artístico-metafísicas, as quais dominavam, no essencial, aqueles escritos: elas são agradáveis, mas insustentáveis". In. Anotação Póstuma (Nachlass) do fim de 1876 - verão de 1877, 23[159]. As obras de Nietzsche, no caso de citadas, seguirão a edição crítica de estudos: NIETZSCHE, Friedrich. Sämtliche Werke. Kritische Studienausgabe. Hg. G. Colli und M. Montinari, Berlin, New York, München: Walter de Gruyter - DTV. 1980 (doravante, KSA). As traduções serão de nossa autoria. ${ }^{3}$ Consultar a primeira seção de Humano, Demasiado Humano, em especial aforismo 10.
} 
filosofia de Schopenhauer na Alemanha. Além de apresentar uma perspectiva crítica quanto à recepção de R. Wagner do pensamento schopenhaueriano, ele recupera ali alguns tratamentos temáticos que - à revelia do que foi feito, com ingenuidade, pelo compositor (e certamente coloca a si próprio, de maneira retrospectiva, como ingênuo), quando fundiu à teoria estética a metafísica da vontade - distanciam-se de meras elucubrações e devaneios metafísicos em direção a uma mais bem fundamentada posição (científica) de Schopenhauer. Nietzsche escreve em A Gaia Ciência 99:

O que tratam de assumir de seu mestre, em primeiro lugar, os discípulos de Schopenhauer na Alemanha? (...) Seria seu rígido sentido dos fatos, sua boa vontade para a clareza e razão, que o faz parecer frequentemente tão inglês e tão pouco alemão? Ou [seria] a força de uma consciência moral intelectual (intelectuellen Gewissens), que o sustentou, durante sua vida, numa longa contradição entre ser e querer e que o impeliu a contradizer-se frequentemente em seus escritos e quase em todos os pontos? Ou a pureza no que concerne à igreja e ao Deus cristão? (...) Ou suas imortais doutrinas da intelectualidade da intuição, da aprioridade (Apriorität) da lei causal, da natureza instrumental do intelecto e da não-liberdade da vontade? Não, isso tudo não fascinou e sequer foi sentido como fascinante $(\ldots)^{4}$.

A admiração de Nietzsche da probidade intelectual de Schopenhauer é um tema que, como parece ser consenso entre os pesquisadores, não estaria inserido naquele processo de radical ruptura que se inicia com Humano, Demasiado Humano. O mesmo, talvez, não poderia se dizer com relação à crítica de Schopenhauer às motivações "teologais" dos moralistas, aqueles que, como ficou conhecido pela famosa epígrafe de Sobre o Fundamento da Moral, "pregam" a moral mas não a "fundamentam”. Que Nietzsche aqui, em A Gaia Ciência 99, exulte a liberdade da orientação do filosofar de Schopenhauer diante dos grilhões do cristianismo, isso não valeria para seu pensamento como um todo e, nessa direção, o contra-argumento de maturidade ao conceito de pessimismo em Schopenhauer precisaria ser mais uma vez mencionado. Nietzsche, já em Para Além de Bem e Mal (em especial no aforismo 186) não enxerga mais essa "emancipação", propugnada pelo seu pessimismo filosófico, do pensar schopenhaueriano ante a moral cristã. Mas com relação à passagem acima citada, resta ainda falar sobre isto que efetivamente parece ter fascinado Nietzsche num momento de plena afirmação da

\footnotetext{
${ }^{4}$ Cf. Gaia Ciência 99 (KSA 3, 453-4).
} 
metodologia das ciências positivas, a saber, "as suas imortais doutrinas da intelectualidade da intuição, da aprioridade da lei causal, da natureza instrumental do intelecto e da não-liberdade da vontade"; que o fato de Nietzsche conhecer, de primeira mão, as premissas que sustentam essas "imortais doutrinas" desde seu primeiro contato com a obra de Schopenhauer, em 1865, isso pouco ilustra o caso aqui em questão. A referência precisa a tais "doutrinas", 17 anos depois de sua primeira leitura de O Mundo como Vontade e Representação e num momento de profunda revisão de sua filosofia, pressupõe uma estratégica bem delimitada. Com ela quer acentuar que Schopenhauer teria pensado a fundo - e isso se confirmaria já com sua tese de doutoramento, Sobre a Quadrúplice Raiz do Princípio de Razão Suficiente - a condição de possibilidade científica não apenas da matemática e da física, mas, sobretudo, da ética a partir de um estreito diálogo com hipóteses que emergiam da (cientificamente enviesada) Naturphilosophie - por isso, não é gratuita a mudança de "pátria" de Schopenhauer, já que Nietzsche na passagem acima ele o vincula ao pensamento inglês.

A importância de temas (científicos) como "intuição intelectual" e "aprioridade da lei causal" foi preterida pelos "discípulos de Schopenhauer" em favor de "excessos e vícios filosóficos" tais como o conceito de gênio, vontade e compaixão, afirma Nietzsche na sequência do aforismo 99 de A Gaia Ciência. No entanto, esses tópicos da filosofia de Schopenhauer parecem ter sido dispensados pelos seus seguidores em favor de temas mais faustosos, questões que, no fundo, dignificavam ao próprio discípulo (e nesse sentido parece clara a autocrítica de Nietzsche ao seu período "metafísico”). Trata-se então de despir Schopenhauer de suas contradições ontológicas, de sua até então influenciável tentativa de pensar o ser a partir do querer, para pensá-lo como um divisor de águas da filosofia do XIX, enquanto um pensador que se encontrava efetivamente no limiar entre o antigo (metafísico) modo pensar e o novo (científico). A passagem de A Gaia Ciência 99 demonstra que Nietzsche vislumbrava (e aqui ele segue de perto o "inglês prussiano", Paul Rée $\left.^{5}\right)$ pontos decisivos do legado filosófico de Schopenhauer, especialmente aquele que flertava com a metodologia da ciência positiva da época. Isso para dizer que talvez não seria mesmo tão fácil afirmar uma "ruptura" de perspectiva entre o Nietzsche professor de filosofia clássica na Basileia e aquele de Humano, pois como é amplamente conhecido, sua

\footnotetext{
${ }^{5}$ Cf. RÉE, Paul. Der Ursprung der moralischen Empfindungen. Bonn: Denkmal Verlag, 2005. Em especial, primeira seção, págs. 30 ss.
} 
admiração pelo alcance da interpretação científica data de alguns anos antes da escritura de O Nascimento da Tragédia. Quase sempre, porém, seu interesse intermediário pelos procedimentos das ciências da natureza, da fisiologia, da biologia, da psicologia é remetido a um núcleo de pensadores e cientistas alemães que o jovem Nietzsche, na verdade, teria lido ainda na segunda metade da década de 1860. A lista é numerosa, mas sua fonte comum parece ter sido o livro de F. A. Lange, A História do Materialismo e Crítica de seu Significado Presente. Já a mesma leitura que Nietzsche fez de O Mundo como Vontade e Representação, um ano antes, é alinhavada, na pesquisa especializada, a um notório interesse pela metafísica da vontade. De acordo com a grande maioria dos intérpretes, deve-se creditar ao livro de Lange a fonte dos argumentos nietzscheanos, na segunda metade da década de 1860, que direcionaram seu interesse pelas ciências da época, em especial pela fisiologia, metodologia essa que foi trabalhada por ele - geralmente em anotações e textos póstumos, porém não de um modo estritamente aleatório e experimental - com um escopo diverso daquele, publicado em sua primeira obra, de uma metafísica estética.

Esse artigo não pretende, no entanto, perseguir essa possível vinculação do modo como Nietzsche, em seu período intermediário, está interpretando o valor científico da intuição intelectual e da "aprioridade" do princípio de causalidade em Schopenhauer, mas, isto sim, discutir no que consiste, segundo o próprio autor d'O Mundo, o caráter científico de sua tese sobre ambas as doutrinas, as quais estão sendo tematizadas por motivos que, por ora, não calham ser retomados em detalhe ${ }^{6}$.

Adiante, pretendemos apresentar os argumentos schopenhaueriano sobre o aspecto fisiológico da percepção empírica, com o intuito de, a partir daí, abrir uma nova perspectiva acerca da vinculação "inglesa" (aquela que prescreve as diretrizes científico-metodológicas de investigação dos fenômenos) do pensamento de Schopenhauer, já que nos parece viável apontar como a interpretação científico-natural, tão presente na influente obra de Lange, teria também forte presença na teoria do conhecimento (especialmente em sua "doutrina" da intuição intelectual) do grande educador de Nietzsche. Em A Gaia Ciência, torna patente que Schopenhauer seria sim herdeiro do projeto positivista da filosofia da natureza que, na Alemanha, ganhou força na primeira metade do século XIX, e que essa herança poderia ser

\footnotetext{
${ }^{6}$ Em linhas gerais, esses motivos versam sobre o horizonte da dissertação de mestrado, ao contexto do capítulo ao qual essa intervenção, agora tornada artigo, pertencia.
} 
encontrada naquilo que é efetivamente valioso na filosofia schopenhaueriana, a saber, a intuição intelectual e o apriorismo da causalidade, mas que, por preciosismo de seus "discípulos", foi preterido em detrimento de temáticas supérfluas. Na filosofia de Schopenhauer, como a pesquisa mais avançada já mostrou, é possível encontrar a tentativa de unir argumentos extraídos do idealismo transcendental de Kant com teses da Naturphilosophie, especialmente naquilo que respeita a uma moderada hipótese fisiológica do modo de conhecer. ${ }^{7}$ Schopenhauer não se limita a explicar como ocorre o conhecimento a priori de objetos empíricos; procura justificar por que (em clara alusão a capacidade demonstrativa da ciência) ele deve ocorrer de tal e tal maneira e não de outra. Como discutiremos nas linhas que se seguem, a afecção empírica e o conhecimento a priori dessa afecção operam, no interior da filosofia schopenhaeuriana, em dois registros, fisiológico e transcendental, de um mesmo processo.

\section{Filosofia transcendental e fisiologia em torno do debate com Kant}

Peter Welsen aponta para essa importante conjunção entre filosofia transcendental e fisiologia nas ponderações de Schopenhauer sobre o procedimento da percepção empírica. ${ }^{8}$ Segundo Welsen, Schopenhauer, por um lado, insiste na manutenção das formas da sensibilidade (espaço e tempo) e do entendimento (reduzindo, por sua vez, as categorias kantianas a uma: a causalidade) no conhecimento a priori dos objetos empíricos; e, por outro, inova ao rejeitar a posição compatibilista de Kant, segundo a qual a percepção empírica está condicionada à hipótese do realismo empírico - objetos que independem das nossas capacidades cognitivas -, substituindo-a por uma sofisticada fisiologia da afecção. Aquilo que interessaria a Schopenhauer seria defender que a própria efetividade empírica (empirische Wirklichkeit) é produto de atividades fisiológicas e transcendentais operadas, imediatamente, pelos nossos órgãos sensíveis (Sinnesorgane) e pelo nosso intelecto

\footnotetext{
7 "Acompanhando o debate Fichte-Schelling acerca da realidade do mundo exterior, portanto acerca do nascimento da Naturphilosophie, já desconfiada do fundo abismal do cosmos não alcançável pela razão, a gênese do sistema de Schopenhauer, apesar de em seus primórdios muito devedora de Kant, sempre se preocupa ao mesmo tempo em exprimir o seu descontentamento com o negativismo da primeira crítica". BARBOZA, Jair., Infinitude subjetiva e estética: natureza e arte em Schelling e Schopenhauer. São Paulo: Editora Unesp, 2003, pág. 99.

8 WELSEN, Peter. Schopenhauers Theorie des Subjekts: ihre transzendentalenphilosophischen, anthropologischen und naturmetaphysischen Grundlagen. Würzburg: Königshausen und Neumann, 1995, págs. 232 ss.
} 
(cérebro). De acordo com essa concepção, a coisa em si, "enquanto existente em absoluto", isto é, independente de espaço, tempo e causalidade, bem como dos nossos órgãos sensoriais, é uma contradictio in adjecto. Sustentá-la é admitir, nos dizeres do filósofo, que seria possível o conhecimento de um objeto sem o sujeito que o conhece, e vice-versa. ${ }^{9} \mathrm{~A}$ totalidade da realidade empírica - o mundo - só existe enquanto representação, portanto, somente para o sujeito: eis, grosso modo, o ponto de partida e, simultaneamente, de chegada do primeiro livro de $O$ Mundo como Vontade e Representação (doravante, WWV $\mathrm{I})^{10}$.

Sobre as considerações kantianas acerca da relação sujeito-objeto, Schopenhauer argumenta, nos Fragmentos para a história da filosofia, que Kant não estaria autorizado, a partir da doutrina alicerçada pela Estética e pela Analítica Transcendental, a concluir que, "para cercear a pretensão da sensibilidade", é mister pressupor "um conceito-limite (Grenzbegriff)", a saber, o conceito de coisa em si, a fim de justificar o modo da afecção (espacial) de objetos externos. ${ }^{11} \mathrm{Na}$ Crítica da Filosofia Kantiana (doravante, KK), completa, salientando que a saída para o problema da afecção empírica é concebida por Kant como uma espécie de inversão do ônus da prova, tal como pode-se ler na Crítica ao quarto paralogismo da psicologia transcendental:

A famigerada questão, que é devida à comunidade de pensadores e prolongadores, seria, se se segrega todo imaginário, a seguinte: como é possivel em um sujeito pensante em geral intuições externas, a saber, aquelas do espaço (de um preenchimento, [da] figura e [do] movimento do mesmo). Para essa questão, porém, nenhum homem é capaz de encontrar uma resposta e jamais se poderá preencher a lacuna do nosso saber, mas apenas designar (bezeichnen) para isso que aos fenômenos externos é atribuído um objeto transcendental (tranzsendentalen Gegenstande), que é a causa desse tipo de representação; nós, de modo

9 „Ich glaube, daß ein altes, eingewurzeltes, aller Untersuchung abgestorbenes Vorurteil in Kant der letzte Grund ist von den Annahme eines solchen absoluten Objekts, welches an sich, d.h. auch ohne Subjekt, Objekt ist““. KKP, pág. 596. Nessa mesma direção, lê-se em $W W V$ II, § 19, pág. 260: „Wie nämlich kein Objekt ohne Subjekt sein kann, so auch kein Subjekt ohne Objekt, d.h. kein Erkennendes ohne ein von ihm Verschiedenes, welches erkannt wird“. As obras de Schopenhauer serão citadas conforme a seguinte edição: SCHOPENHAUER, A. Sämtliche Werke in fünf Bänden. Hg. Wolfgang Frhr. Löhneysen. Suhrkamp: Stuttgart/Frankfurt am Mein, 1986. Traduções de nossa autoria.

10 "Tudo que pertence e pode pertencer ao mundo está inevitavelmente investido desse estar condicionado pelo sujeito (Bedingtsein durch das Subjekt), existindo apenas para este”. $M$, pág. 44; WWV, pág. 32.

${ }^{11}$ KANT, I. Crítica da razão pura (doravente, $\mathrm{KrV}$ ), B 307 a 311. As obras de Kant serão citadas conforme a edição: KANT, I. Werke in sechs Bänden und Wörterbuch. Hg W. Weischedel. Wissenschaftliche Buchgesellschaft: Berlin, 2004. Traduções de nossa autoria. 
algum, o conhecemos (erkennen), bem como jamais [pode] ser recebido dele algum conceito ${ }^{12}$.

Atribui-se claramente, nesse passo, ao opositor - no caso, qualquer filósofo que pretenda resolver a questão - aquilo que o proponente deveria provar, uma vez que suscitou o problema. Assim, parece notório a Schopenhauer que Kant, ao não oferecer uma resposta cabal, partiu de um pressuposto indemonstrável: ou se admite que um tal objeto transcendental é causa do fenômeno apreendido pela forma do espaço, ou qualquer resposta que busque explicar o modo como se realiza a percepção empírica é mera conjectura, consequentemente, não mais é possível um conhecimento objetivo da realidade empírica. Ora, a fim de desvelar aquela petitio principii de Kant, Schopenhauer aponta, pelo menos, duas "premissas" problemáticas, assumidas por ele, que obstruem, segundo sua perspectiva, uma correta resolução do problema: (i) pressuposição de que o espaço seja a forma da intuição "externa" de objetos e (ii) indefinição do objeto ao qual se aplica a lei de causalidade.

Em $K K$ - para onde o filósofo, não raro, remete o leitor quando em contenda com Kant - argumenta que o objeto da doutrina kantiana é tomado em sinonímia de absoluto, e apoia-se "em um cometimento irresponsável (Windbeutelei) da intuição intelectual". Absoluto a significar que, a despeito da distinção entre objetos "para nós" e objetos "em si”, Kant não identifica ambos os aspectos com o conceito de representação. O sentido de objeto (Objekt), enquanto sinônimo de "coisa em si" ou de "noumenon", segundo Kant, não está firmemente vinculado às capacidades cognitivas do sujeito, portanto, é pensado como incondicionado. Somente o objeto (Gegenstand), enquanto "fenômeno (Erscheinung)", é tomado como sinonímia de "representação". ${ }^{13}$ No que se refere à segunda premissa,

${ }_{12} \mathrm{KrV}$, A 393. Segundo P. Welsen, Kant necessitaria adotar uma "metaposição" para justificar o problema da afecção empírica em sua doutrina. Cf. WELSEN, P. op. cit. pág. 28 ss.

${ }^{13}$ Cf. $K K$, pág. 596. A distinção, feita por Kant, entre Gegenstand e Objekt nem sempre é respeitada na $\mathrm{KrV}$. Consultar, por exemplo, $\mathrm{KrV}$, A 288 / B 344, na qual escreve: "O entendimento limita, dessa forma, a sensibilidade, sem estender por isso o seu próprio campo e, porquanto ele a adverte que ela não pode arrogar para si coisas em si mesmas, mas sim apenas fenômenos (Erscheinungen), então ele representa para si (denkt sich) um objeto (Gegenstand) em si mesmo (an sich selbst), porém apenas como objeto transcendental (transzendentalen Objekt); este é a causa (Ursache) do fenômeno (conseqüentemente não o próprio fenômeno) e não pode ser pensado nem como grandeza, nem como realidade (Realität), nem como substância (pois esses conceitos exigem sempre formas sensíveis [sinnliche Formen], nas quais eles determinam um objeto); do que se segue que é completamente desconhecido se ele (subent. o objeto) se encontra em nós ou é externo a nós; se ele é, simultaneamente, suprimido (aufgehoben) com a sensibilidade ou se, ao extrairmos esta, ele permaneceria". Nesse argumento a favor do compatibilismo, sustenta Kant que o entendido "denkt sich" (representa para si) um objeto que é a causa do fenômeno; a esse objeto que é figurado pelo 
salienta, agora nos Fragmentos, que Kant, assim como Locke, tomou "o princípio de causalidade como algo absoluto (als ein absolutes) e pôde, legitimamente, concluir por meio disso a coisa exterior, que existe efetivamente independente de nós". ${ }^{14}$ Faz-se notar que o uso equivocado do princípio de causalidade segue-se, necessariamente, da também equivocada distinção, segundo seu aspecto, do objeto. Qualquer forma transcendental aplicada a algo que é "estranho (fremd)" ao sujeito, ultrapassa os limites da cognoscibilidade, tornando, dessa forma, seu uso indevido.

O rigor demonstrativo (científico) com que Schopenhauer buscou identificar os conceitos objeto (Gegenstand) e representação (Vorstellung) não aponta meramente para uma contenda com a filosofia kantiana, mas indica a coesão com a qual buscou conceber sua própria doutrina da afecção empírica. Para Schopenhauer, é apenas por meio de uma intersecção entre fisiologia e filosofia transcendental que as contradições entre afecção empírica e conhecimento a priori de objetos pode ser dissolvida.

Schopenhauer jamais deixou de reconhecer os avanços realizados por Kant no que respeita à teoria do conhecimento, principalmente no que se refere à sua origem, possibilidade e limite. Kant, assim como Platão e os Vedas, é um dos fulcros de seu sistema. O filósofo de Königsberg realizou, segundo Schopenhauer, o que nenhum outro filósofo realizara até então: vislumbrou, com mérito, que a parte formal do conhecimento pode se adequar àquela empírica, e criou daí a chave para o conhecimento a priori da efetividade. Como assume em A Quadrúplice Raiz do Princípio de Razão Suficiente (doravante, $S G$ ), as teses referentes à doutrina da Estética Transcendental são amplamente adotadas pela sua filosofia. Que o espaço seja a forma responsável pela apreensão simultânea (Nebeneinander) dos objetos e que o tempo seja a forma responsável pela apreensão sucessiva (Nacheinander) daqueles; tais enunciados não podem ser contraditos. No domínio da matemática, especificamente a geometria e aritmética, os objetos (figuras e números) são construídos, a priori, pelas formas da sensibilidade, espaço-temporalmente, em consonância com a causalidade, que fornece a regra para que uma figura possa ocupar

entendimento, denomina objeto transcendental. O objeto transcendental, sustenta o reconhecido intérprete, $\mathrm{H}$. Alisson, não é simplesmente considerado como distinto de nossas representação, mas também como independente das condições da sensibilidade, sob as quais um objeto físico pode ser intuído pela razão humana. Cf. ALISSON, H. Kant's Transcendental Idealism. New Haven and London: Yale University Press, 1983, pág. 244-5.

${ }^{14} P$ I, pág. 118. Schopenhauer, em $K K$ pág. 588 , reconhece que esta crítica fora perpetrada primeiramente pelo seu professor, G. E. Schulze. 
lugar no espaço, e para que números possam ser deduzidos, sucessivamente, em operações matemáticas. Porém, no que respeita à sua fundamentação da física, e mantendo a coerência de seu sistema, que recusa uma percepção espacial de objetos "externos", distancia-se da posição de Kant, ao demonstrar como espaço e tempo apreendem, na física, o objeto, imediatamente. O modo como a sensibilidade apreende os objetos da experiência, de acordo com a filosofia especulativa de Schopenhauer, delineia um importante ponto de distanciamento em relação a Kant.

Para Kant, a apreensão espacial está em direta relação com o objeto que nos é dado (gegeben); daí se infere que este é apreendido imediatamente. ${ }^{15}$ À representação do espaço não está associado o conceito "puro", a significar independência da experiência. Somente o tempo, forma mediata de apreensão dos objetos, possui essa característica. Essa distinção é imprescindível, para compreender o funcionamento do Esquematismo Transcendental na síntese do múltiplo pelos conceitos.

Schopenhauer, por sua vez, não identifica sentido externo e interno no eixo da sua relação com o objeto dado à nossa experiência. Se, para Kant, o objeto deve ser dado aos nossos sentidos, para daí se extrair sua representação, para Schopenhauer, espaço e tempo não são formas pelas quais nos relacionamos com objetos externos. ${ }^{16}$ Sentido interno e externo não se diferenciam pela sua aplicação a, ou ordenamento de, objetos mediatos ou imediatos; ou dito de outra maneira: não se diferenciam em sua relação com um objeto dado ou representado, mas antes se diferenciam na determinação de estímulos percebidos pelos nossos órgãos sensitivos. ${ }^{17}$ Sentido interno ou externo; objeto externo ou objeto da nossa representação; tais distinções são apenas resultado de síntese operada pelo entendimento. Na ordenação de estímulos proposta por Schopenhauer as formas do espaço e do tempo estão em estreita ligação com o princípio de causalidade, pois necessitam dele para organizar, seja simultaneamente, seja sucessivamente, os estímulos percebidos segundo uma regra. A causalidade, enquanto regra do entendimento, determina "não somente a sucessão de estados no mero tempo, mas essa sucessão em referência a um espaço determinado; não a existência em um lugar qualquer, mas neste lugar e num tempo

${ }^{15} \mathrm{KrV}$, B 42 - A 26.

${ }^{16}$ Sobre o contra-argumento oferecido por Schopenhauer, consultar: $K K$, pág. 591 ss.

${ }^{17}$ Cf. $S G$, pág. 45 ss.; $W W V$ I, pág. 40 ss. 
determinado". ${ }^{18}$ É o entendimento, argumenta Schopenhauer em $S G$, que liga (verbindet), não somente os fenômenos, mas também “aquelas formas heterogêneas da sensibilidade".

Sob esse aspecto, o espaço não pode ser assumido como forma da apreensão de objetos exteriores ao sujeito, pois, se assim fosse, o entendimento seria levado, necessariamente, a supor, como causa dessa percepção, um objeto "absoluto", o que ampliaria, para além das capacidades cognitivas do sujeito, a relação entre causa e efeito. O princípio que sustenta a tese do realismo empírico é manifestamente rejeitado. Não é contraditório afirmar que haja fenômeno (Erscheinung) sem que exista algo que apareça (erscheint), isto é, sem existir um objeto “em si”. Pelo contrário, é ao assumir essa posição que, segundo Schopenhauer, Kant revelou o "calcanhar de Aquiles" de sua teoria da afecção. ${ }^{19}$ Sendo o mundo condicionado às capacidades cognitivas do sujeito, nada há para além da mera representação. ${ }^{20}$ Consequentemente, Schopenhauer, levando a termo tal enunciado, interpreta, de maneira distinta daquela de Kant, o modo como se realiza a construção do objeto. O procedimento pelo qual estímulos sensíveis são tornados representação delineia os principais aspectos de sua perspectiva sobre o modo da afecção e o resultado desta.

Acerca da questão: “o que nos afeta?”, argumenta Schopenhauer que espaço, tempo e causalidade são formas aplicadas, imediatamente, a estados da matéria (Zustände der Materie) e não à representação de um objeto percebido de fora, como propôs Kant na primeira Crítica. Matéria, tal como Schopenhauer a concebe em $W W V$ I, é o conteúdo sensível das formas. A matéria possui como principal propriedade o "fazer-efeito (wirken)". Essa propriedade é imprescindível para se pensar elementos móveis no espaço e no tempo ${ }^{21}$. Só há determinação de uma causa no espaço e no tempo se e somente se há matéria, pois aquelas formas só determinam estados que possuam materialidade sensível capaz de fazer-efeito, e jamais determina uma "coisa real da imaginação (das reale Ding der Phantasiebilde)"22. Segundo essa concepção, os sentidos devem oferecer o múltiplo

${ }_{18} W W V$ I, pág. 39

$19 P \mathrm{I}$, pág. 113.

20 „Objekt für das Subjekt sein, und unsre Vorstellung sein, ist das Selbe. Alle unsre Vorstellungen sind Objekte des Subjekts, und alle Objekte des Subjekts sind unsre Vorstellungen. Nun aber findet sich, daß alle unsre Vorstellungen unter einander in einer gesetzmäßigen und der Form nach a priori bestimmbaren Verbindung stehn, vermöge welcher nichts für sich Bestehendes und Unabhängiges, auch nichts Einzelnes und Abgerissenes, Objekt für uns werden kann“. $S G$, pág. 41.

${ }^{21} W W V$ I, pág. 40; $K K$, pág. 600 ss.

$22 K K$, pág. 600 . 
(Mannigfaltig) como percepção (Empfindung) ao entendimento, a partir do que ele, "por meio da aplicação da lei de causalidade e sobre o fundamento da intuição pura, espaço e tempo, constrói (aufbaut) o magnífico mundo objetivo em nossa cabeça (die wundervolle objektive Welt in unserm Kopf)"23. $\mathrm{Na}$ recepção de estímulos, nosso corpo percebe (wahrnimmt) modificações (Veränderungen) sofridas, imediatamente. São a estados desses estímulos percebidos, que fazem efeito sobre nossos sentidos, que o entendimento aplica uma causa, no espaço e no tempo - e não a um objeto dado. A esses estados que se efetivam Schopenhauer denomina Materie $^{24}$.

Todo o procedimento perceptivo se encontra no sujeito, melhor dizendo, no corpo $^{25}$. É a partir desses estímulos sentidos pelo olho, ouvido, pele etc., e fornecidos ao entendimento, que o mundo, isto é, a realidade empírica, torna-se, para o sujeito, representação. O resultado da afecção empírica é, então, expresso pela proposição: $o$ mundo é minha representação. Mas há aqui, notadamente, dois registros distintos: (i) recepção de estímulos pelos órgãos sensoriais e (ii) aplicação da lei de causalidade, no domínio da sensibilidade, à matéria. Julgamos que, para se compreender esses dois registros, é necessário, antes, pressupor um "duplo aspecto" do argumento schopenhaueriano: o primeiro, referente à fisiologia da percepção, e o segundo referente ao seu caráter transcendental, que diz respeito ao resultado daquela percepção.

\section{3. “Stoff” e “Materie": sobre a percepção de estímulos e a intuição intelectual do objeto}

Ora, sabemos que a multiplicidade fornecida pelos órgãos sensíveis é, para o entendimento que julga, matéria. Portanto, como dito, o ofício transcendental do

\footnotetext{
${ }^{23} W W V$ II, pág. 40.

${ }^{24} G$, pág. 50, argumenta: „Ganz falsch hingegen ist es, wenn man nicht den Zustand, sondern die Objekte nennt". Sobre a rejeição por parte de Schopenhauer do objeto "dado" kantiano, cf. KK pág. 591 ss.

25 “É certo [que] Schopenhauer introduz modulações até então impensáveis no pós-kantismo, mediante um acento fortemente fisiológico de seu pensamento, ao descartar a intuição intelectual mística como ponto de partida da sua filosofia: agora, o corpo (Leib) aparece como a encruzilhada do conhecimento, que não brota incondicional e imediatamente do intelecto, ou seja, da reflexão da reflexão, já que esta é derivada, reflexo de algo diferente do conhecer conceitual. A metafísica se desfaz do primado do intelecto, do racional, e em seu lugar entram em cena os próprios nervos como coordenadas de acesso ao mais real do mundo". In: BARBOZA, J. op. cit., pág. 103-4.
} 
entendimento e da sensibilidade é executar a síntese dos estados dessa matéria (o conteúdo sensível). Resulta daqui a afirmação de Schopenhauer segundo a qual a atividade do entendimento - sua síntese de estados da matéria operada no espaço e no tempo - é intuitiva. No entanto, seguindo unicamente o viés transcendental do argumento, não poderíamos compreender a função dos órgãos sensíveis na recepção e fornecimento de estímulos ao entendimento.

Schopenhauer insiste em confrontar ao dogmatismo realista de Kant, de acordo com o qual o objeto é mero efeito no sujeito, sua teoria transcendental, com marcantes traços, ressalta Jair Barboza, da Naturphilosophie. Aos órgãos sensoriais é atribuída, como dito, a função receptiva de estímulos. "O que o olho, o ouvido e a mão sentem não é intuição, mas 'meros dados (bloßen Data)'. Só quando o entendimento passa do efeito à causa é que o mundo aparece como intuição (...)"26. Os Data percebidos pelos órgãos dos sentidos caracterizam que o registro da apreensão é meramente físiológico, distinto daquele transcendental que diz respeito ao uso da sensibilidade e do entendimento na determinação dos mesmos. Perceber a modificação sofrida, por exemplo, pelos olhos, nada mais significa que uma "percepção (Empfindung) surge a partir do nervo óptico sob motivação de estímulos luminosos, que está associada à operação da retina" ${ }^{27}$. Desmembrando em etapas, a retina opera fornecendo os dados para o cérebro (intelecto), e este os processa, no instante em que a eles atribui uma "razão de ser". Enquanto no domínio fisiológico os "meros dados" são concebidos como a parte concreta da afecção (aquilo que nos afeta), por sua vez, no registro transcendental, é a matéria (Materie) que constitui o conteúdo ao qual se aplicam as formas a priori do conhecimento. Schopenhauer, acreditamos, faz sempre notar, em seu escritos, essa distinção conceitual entre (o conceito) Materie e (os termos) "meros

\footnotetext{
${ }^{26} W W V$ I, pág. 42.

$27 W W V$ II, ,, Die Lehre von der anschaulichen Vorstellung “, pág. 43. À título de ilustração, vale mencionar a seguinte passagem da obra F. A. Lange, na qual argumenta o seguinte: „Man bringt auf der weissen Fläche einen schwarzen Stab an und läßt die Mitte desselben auf den blinden Fleck fallen. Der Stab erscheint vollständig, einerlei, ob er vollständig ist oder ob er an der blinden Stelle unterbrochen ist. Das Auge macht gleichsam einen Wahrscheinlichkeitsschluß, einen Schluß aus der Erfahrung, eine unvollständige Induktion. Wir sagen: das Auge macht diesen Schluß. Der Ausdruck ist absichtlich nicht bestimmter, weil wir damit nur jenen gesamten Kreis der Einrichtungen und Vorgänge vom Zentralorgan bis zur Netzhaut kurz bezeichnen wollen, dem man auch die Tätigkeit des Sehens zuschreibt. Wir halten es für methodisch unzulässig, in diesem Falle das Schließen und das Sehen als zwei gesonderte Akte von einander zu trennen. Dies kann man nur und der Abstraktion tun. Wenn man an dem wirklichen Vorgang nicht künstlich deutet, so ist in diesem Falle das Sehen selbst einer Gesichtsvortellung, wie er sich in andern Fällen in der Form sprachlich ausgedrückter Begriffe vollzieht“". In: LANGE, F. Geschichte der Materialismus und Kritik seiner Bedeutung in der Gegenwart, Band II, 1921, pág. 403-4.
} 
dados", "percepções", "estímulos" etc., sendo estes, por sua vez, reunidos no conceito Stoff - no mais das vezes traduzido também, equivocadamente nesse caso, por matéria.

A principal propriedade da matéria (Materie), afirma Schopenhauer, é "fazer-efeito" 28 . Sustenta o filósofo de Frankfurt que caso a matéria não possuísse essa propriedade, a simultaneidade e a sucessão não seriam possíveis. São possíveis, uma vez que a estados de "algo que se efetivou", no espaço e no tempo, é aplicada uma causa, segundo um princípio científico: o conjunto ou série causal possibilita a mudança, consequentemente, o movimento. A matéria (Materie) se apresenta às formas da sensibilidade e ao entendimento como conteúdo sensível que se efetiva. Do ponto de vista de suas considerações no domínio transcendental, matéria, causalidade, tempo e espaço são termos preponderantes não somente para a determinação a priori do objeto, mas, principalmente, para sua criação ${ }^{29}$. Por outro lado, a tese sobre as modificações percebidas pelos órgãos sensíveis (de acordo com a qual meros dados recebidos pelos olhos, ouvido, pele etc., nada nos informam sobre o objeto, uma vez que este é resultado da síntese promovida pelas formas da sensibilidade e pelo entendimento e não, propriamente, pelos cinco sentidos) - esse argumento, consideramos, deve ser entendido em um outro âmbito que não aquele que caracteriza os principais aspectos de sua filosofia transcendental. Se o conteúdo sensível ao qual se aplicam as formas a priori do conhecimento é definido pelo conceito Materie, diferentemente, Schopenhauer grafa, em geral, Stoff para aqueles Data percebidos pelos órgãos dos sentidos.

\footnotetext{
${ }^{28}$ Em $W W V$ I, pág. 41, Schopenhauer afirma a identidade entre os conceitos matéria e causalidade. Sobre a capacidade de "fazer efeito", cf. $K K$, pág. 600. Influência direta dessa perspectiva pode ser notada na obra de juventude de Nietzsche, A Filosofia na Época Trágica dos Gregos, quando cita exatamente essa mesma passagem da obra de Schopenhauer, a fim de estabelecer um paralelo entre a concepção heraclitiana de representação intuitiva (espaço-temporal) e aquela de Schopenhauer: „Heraklit hat als sein königliches Besitzthum die höchste Kraft der intuitiven Vorstellung: (...) Die intuitive Vorstellung aber umfaßt zweierlei: einmal die gegenwärtige, in Allen Erfahrungen an uns heran sich drängende bunte und wechselnde Welt, sodann die Bedingungen, durch die jede Erfahrung von dieser Welt erst möglich wird, Zeit und Raum. Denn diese können, wenn sie auch ohne bestimmten Inhalt sind, unabhängig von jeder Erfahrung und rein an sich intuitiv percipirt, also angeschaut werden. Wenn nun Heraklit in dieser Weise die Zeit, losgelöst von allen Erfahrungen betrachtet, so hatte er an ihr das belehrendste Monogramm alles dessen, was überhaupt unter das Bereich der intuitiven Vorstellung fällt. So wie er die Zeit erkannte, erkannte sie zum Beispiel auch Schopenhauer, als welcher von ihr wiederholt aussagt: daß in ihr jeder Augenblick nur ist, sofern er den vorhergehenden, seinen Vater, vertilgt hat, um selbst ebenso schnell wieder vertilgt zu werden, daß Vergangenheit und Zukunft so nichtig als irgend ein Traum sind, Gegenwart aber nur die ausdehnungs- und bestandlose Grenze zwischen beiden sei, daß aber, wie die Zeit, so der Raum und wie dieser, so auch alles, was in ihm und der Zeit zugleich ist, nur ein relatives Dasein hat, nur durch und für ein Anderes, ihm Gleichartiges d. h. wieder nur ebenso Bestehendes sei“. In. KSA I, págs. 823-4.
}

${ }^{29} W W V$ I, pág 42. 
Submetida às formas a priori do conhecimento, os estados da matéria são sintetizados pelo sujeito segundo uma regra, a qual define que, para todo efeito percebido, há um fundamento. Ao remeter esse efeito percebido a uma causa, o entendimento cria o que Schopenhauer nomeia ora de intuição do objeto, ora de representação ${ }^{30}$. Entretanto, adverte o próprio Schopenhauer na seção 18 de $W W V$ II, a representação “é um processo fisiológico muito complicado (ein sehr komplizierter physiologischer Vorgang) no cérebro de um animal, cujo resultado é exatamente a consciência de uma imagem". Na medida em que o efeito promovido pela matéria é remetido a uma causa pelo entendimento; e na medida em que uma representação, uma imagem, é criada, pois pensada como causa, tem-se, então, uma genuína intuição intelectual do objeto. A aparição (Erscheinung) ou intuição do objeto está condicionada a uma regra, que só tem validade no espaço e no tempo. Portanto, enquanto tal regra é a propriedade essencial do entendimento, a intuição criada daí é intelectual.

O conceito Stoff, por sua vez, é o conteúdo recebido, imediatamente, pelos órgãos dos sentidos (e não pelas formas). Em $G$, Schopenhauer aponta para o que chama de "grande abismo (große Klufte)" entre a percepção da matéria bruta (der rohe Stoff) oferecida pelos órgãos dos sentidos e a intuição (Anschauung) criada pela ação do entendimento sobre a matéria no espaço e no tempo ${ }^{31}$. O conceito Stoff não possui nenhuma referência no domínio de suas considerações sobre conhecimento transcendental; nesse domínio, se vale do termo Materie. Ao serem ambos os conceitos assumidos como conteúdo sensível - o primeiro como o concreto dos órgãos sensoriais e o segundo das formas - Schopenhauer estabelece, notadamente, entre eles, um elo. Essa correlação entre Stoff e Materie é melhor definida no contexto do seguinte argumento: a intuição objetiva do mundo corpóreo (registro transcendental) deve partir da afecção de Data (registro fisiológico) que estimulam e provocam certas modificações sensíveis em nossos olhos, ouvidos etc. Enquanto oferecidas, como multiplicidade, ao entendimento (cérebro), são processadas segundo um princípio. Para Schopenhauer, o elemento homogêneo ao entendimento e aos órgãos dos sentidos é o espaço. $O$ entendimento se serve da forma a

\footnotetext{
30 “As mudanças que cada corpo animal sofre são imediatamente conhecidas, isto é, sentidas, e, na medida em que esse efeito é de imediato relacionado à sua causa, origina-se a intuição desta última como um objeto". In. $W W V$ I, pág. 42.

$31 S G$, pág. 70.
} 
priori do espaço para perceber tais modificações sensíveis, e, a partir desse procedimento, conhecemos, com rigor científico, a efetividade empírica.

Para se compreender a sutil transição realizada do registro fisiológico para o registro transcendental, deve-se levar em consideração o sentido correlato daqueles dois conceitos. Stoff a significar que os órgãos sensoriais perceberam simples Data; Materie a significar que um estímulo, uma percepção "wirkt" (faz efeito). As modificações sofridas pelos órgãos são agora recebidas pelo entendimento, que lhes confere uma causa. Essa correlação dos dois conceitos ora examinados é referendada por uma passagem dos Fragmentos. Ao buscar responder a seguinte questão: o que nos afeta e qual o resultado dessa afecção, Schopenhauer se dirige, primeiramente, para a origem do conceito Stoff. Argumenta que...

[não] se pode encontrar o Stoff em parte alguma da nossa percepção empírica (Sinnesempfindung): pois existe uma modificação (Veränderung) que se apresenta ou à retina, ou aos nervos auditivos, ou à ponta dos dedos, a qual introduz (einleitet) a representação intuitiva; ou seja, transfere o aparato completo de nossas formas cognitivas já prontas para aquele cenário, cujo resultado é a sensação de um objeto externo. Antes de tudo, é aplicada, a priori, a lei de causalidade àquela modificação percebida nos órgãos dos sentidos, por meio da necessária e infalível função do entendimento. Esse conduz com sua segurança e certeza a priori a uma causa daquela modificação, a qual, porquanto não está no arbítrio do sujeito, apresenta-se agora para ele como exterioridade (als ihm Äußerliches), [que é] uma propriedade que contém, primeiramente, sua significação mediante a forma do espaço. O próprio entendimento acrescenta, para esse ofício, o espaço, pelo que, sensivelmente, apresenta aquela causa pressuposta necessariamente como um objeto no espaço, que porta em si as modificações provocadas em nossos órgãos sensíveis como [sendo] sua propriedade ${ }^{32}$.

Primeiramente, deve-se indicar a importância do verbo einleiten (introduzir, fazer iniciar) na economia do argumento. No registro fisiológico, a modificação que é sentida pelos órgãos sensoriais é identificada com o conceito Stoff (conteúdo sensível percebido). Stoff, sob esse aspecto, é mero dado percebido pelo nosso aparato sensorial. O entendimento, ao receber tal modificação, aplica-lhe uma regra, no espaço, fornecendo a esse conteúdo percebido propriedades tais como materialidade, impenetrabilidade, grandeza, exterioridade e, até mesmo, como mostrado em Sobre a Visão e as Cores, cor. Ao operar sobre aquilo que tomou como "efeito" agindo nos órgãos sensíveis, o

${ }^{32}$ P I, pág. 117.

“(...) O mundo como representação (...) é antes de tudo apenas um fenômeno fisiológico”: Intuição intelectual e percepção empírica em Arthur Schopenhauer 
entendimento busca, segundo seu ofício, uma causa. Sob esse aspecto, “introduz” uma representação, um objeto, que é pensado como causa. Somente no contexto dessa relação entre o efeito percebido pelo entendimento e sua causa é que o conceito representação adquire sentido na demonstração do modo da intuição. Todo o processo antes descrito que possui, como ponto partida, a percepção de um estímulo pelos nossos órgãos sensoriais, e que culmina na criação intelectual do objeto, pode ser desmembrado somente do ponto de vista discursivo. No corpo ele ocorre imediatamente.

Schopenhauer insiste em dizer, tanto na sequência desse supracitado passo quanto no primeiro livro de $W W V \mathrm{I}$, que jamais se poderia chegar à intuição de um objeto se algum tipo de efeito não se realizasse, imediatamente, no nosso organismo, servindo assim de ponto de partida ${ }^{33}$. A relação entre aquilo que se apresenta aos órgãos sensíveis e o conceito Stoff não é concebida no bojo de uma relação causal, como é, por exemplo, a relação entre Zustände der Materie (estados da matéria) e Gegenstand (objeto); antes, é concebida como ponto de partida de procedimentos orgânicos (fisiológicos), portanto de alguma forma sensíveis, que nos levam ao conhecimento daquilo que nos afeta. Stoff é, acima de tudo, esse ponto de partida, uma modificação no corpo ordinária capaz de despertar o entendimento para seu ofício: a criação do mundo. Em $K K$, argumenta categoricamente que é o entendimento quem transforma impressões sensíveis em representações. Conhecer cientificamente um objeto pressupõe, portanto, um procedimento fisiológico muito complicado no cérebro, uma operação que parte do registro orgânico para o domínio das formas a priori. Enquanto que, para Kant, o pressuposto do objeto dado ao sentido externo é conditio sine qua non da percepção empírica, para Schopenhauer, contrariamente, o conceito "objeto", seja tomado em referência externa ou interna, é mero resultado da síntese sensorial e intelectual de impressões.

Com esse argumento, Schopenhauer aponta, concretamente, para o fato de que a filosofia transcendental precisa caminhar de mãos dadas com a ciência natural, especialmente com fisiológica. Na Estética, Kant admite que o espaço é uma representação necessária que fundamenta as intuições externas ${ }^{34}$. É exatamente essa tese que é questionada, em $K K$, pelo filósofo. Que o "empírico" da intuição, tal como é defendido por

${ }^{33}$ Cf. $W W V$ I, pág. 42. Em $S G$, pág. 68, Schopenhauer argumenta: „Denn die Empfindung jeder Art ist und bleibt ein Vorgang im Organismus selbst, als solcher aber auf das Gebiet unterhalb der Haut beschränkt, kann daher, an sich selbst, nie etwas enthalten, das jenseits dieser Haut, also außer uns läge“.

${ }^{34} \mathrm{Kr} V$, A 24. 
Kant, na opinião de Schopenhauer, seja assumido como sendo dado "de fora (von außen)", isso não auxilia na demonstração do "modo como a intuição empírica chega em nossa consciência" "35. Altera-se, na teoria schopenhauriana da afecção, não somente o conceito de “objeto dado" por "impressões", "sensações”, “simples percepções”, "meros dados”, como também o resultado a que se chega é completamente outro. Ao agir sobre a matéria, que é a "portadora de toda modificação (Träger aller Veränderungen)", o entendimento constrói não só $o$ objeto, mas sua intuição espaço-temporal.

No âmbito dos órgãos sensíveis, como já mencionado, não há intuição (Anschauung), mas "simples dados" ". Por esse motivo, o objeto pensado como exterior ao sujeito é figuração (ou criação) do entendimento, na medida em que, segundo Schopenhauer, ao passar do efeito para a causa daquela impressão, cria não somente "uma representação intuitiva objetiva", como também a "projeta para fora" ${ }^{37}$. É por meio desse argumento que defende a tese de acordo com a qual tanto a representação do objeto quanto sua projeção "para fora" - a exterioridade (Äußerliches) -, "surgem a partir sujeito (entspringen aus dem Subjekt)". Por essa razão, o realismo empírico, no contexto da filosofia especulativa de Schopenhauer, não adquire qualquer significação; consequentemente, não se pode afirmar sem mais que haja um fenomenalismo schopenhaueriano, se se entende por fenomenalismo a doutrina segundo a qual, por um lado, só podemos conhecer os fenômenos e não as coisas em si, mas, por outro, não podemos negá-las, porém, antes, temos que admitir sua existência (negativa). Aliás, vale aqui mencionar, seguindo essa mesma via argumentativa, podemos visualizar melhor como o jovem Nietzsche mostra, na mesma direção, reticências quanto a essa noção de fenomenalismo, tal como isso é apresentado pelo seu famoso escrito póstumo Verdade e Mentira em Sentido Extramoral.

\footnotetext{
$35 K K$, pág. 591.

${ }^{36} K K$, pág. 591-2. „Er (subent. der Eindruck) ist aber nichts weiter, als eine bloße Empfindung im Sinnesorgan, und erst durch Anwendung des Verstandes (d.i. des Gesetzes der Kausalität) und der Anschauungsformen des Raumes und der Zeit wandelt unser Intellekt diese bloße Empfindung in eine Vorstellung um, welche nunmehr als Gegenstand in Raum und Zeit dasteht und von letzterem (dem Gegenstand) nicht anders unterschieden werden kann“.

${ }^{37} P$ I, pág. 118. „Nun aber ist ja doch die Sinnesempfindung, welche zu diesem Vorgange den Ausgangspunkt und unstreitig den ganzen Stoff zur empirischen Anschauung liefert, etwas ganz und gar Subjektives, und da nun sämtliche Erkenntniß-Formen, mittelst welcher aus jenem Stoffe die objektive anschauliche Vorstellung entsteht und nach außen projiciert wird (...)“ Schopenhauer, em $S G$, pág. 69, argumenta, com ênfase, que o conceito de "exterioridade" é criado pelo entendimento (cérebro). Cf. comentário WELSEN, P. op. cit. pág. 112. ss.
} 
O objeto externo, enquanto é pensando como causa daquele efeito percebido, é também mero resultado da síntese operada pelo entendimento na matéria, é resultado, argumenta Schopenhauer, em uma anotação manuscrita à $S G$, da "transposição de uma sensação em um objeto como causa (die Übertragung einer Empfindung auf ein Objekt als Ursache)". Não estaríamos aqui muito próximos, guardados importantes pressupostos teóricos, da função da metáfora pensada pelo jovem Nietzsche, enquanto condição de possibilidade da transposição de estímulos em sons e destes em imagens? Para essa questão, seria necessário um novo estudo. Mas certo é que daquela perspectiva schopenhaueriana segue sua derradeira e cientificamente demonstrada tese sobre a condição de possibilidade do conhecimento da experiência: "Em consequência, pois, de nossa consideração objetiva do intelecto", conclui no segundo volume de $W W V$ aludindo mais uma vez ao alcance científico de sua demonstração, “o mundo como representação, tal como ele, estendido no espaço e no tempo, encontra-se e (tal como ele) move-se regularmente de acordo com a rigorosa regra de causalidade, é antes de tudo apenas um fenômeno fisiológico (zunächst nur ein physiologisches Phänomen) (...)"38.

\section{Referências}

ALISSON, H. Kant's Transcendental Idealism. New Haven and London: Yale University Press, 1983.

BARBOZA, J. Infinitude subjetiva e estética: natureza e arte em Schelling e Schopenhauer. São Paulo: Editora Unesp, 2003.

KANT, I. Werke in sechs Bänden und Wörterbuch. Hg. W. Weischedel. Wissenschaftliche Buchgesellschaft: Berlin, 2004.

LANGE, F. Geschichte der Materialismus und Kritik seiner Bedeutung in der Gegenwart, Zwei Bänden, Zehnte Auflage, 1921.

NIETZSCHE, F. Sämtliche Werke. Kritische Studienausgabe. Hg. G. Colli und M. Montinari, Berlin, New York, München: Walter de Gruyter - DTV. 1980.

SCHOPENHAUER, A. Sämtliche Werke in fünf Bänden. Hg. Wolfgang Frhr. Löhneysen. Suhrkamp: Stuttgart/Frankfurt am Mein, 1986.

RÉE, P. Der Ursprung der moralischen Empfindungen. Bonn: Denkmal Verlag, 2005.

\footnotetext{
38 WWV II, pág. 369.
} 
WELSEN, P. Schopenhauers Theorie des Subjekts: ihre transzendentalenphilosophischen, anthropologischen und naturmetaphysischen Grundlagen. Würzburg: Königshausen und Neumann, 1995.

Recebido: 22/12/11

Received: $12 / 22 / 11$

Aprovado: 28/01/12

Approved: 01/28/12 